\title{
A Longitudinal Examination of Net Promoter and Firm Revenue Growth
}

Managers have widely embraced and adopted the Net Promoter metric, which noted loyalty consultant Frederick Reichheld advocates as the single most reliable indicator of firm growth compared with other loyalty metrics, such as customer satisfaction and retention. Recently, however, there has been considerable debate about whether this metric is truly superior. This article (1) employs longitudinal data from 21 firms and 15,500-plus interviews from the Norwegian Customer Satisfaction Barometer to replicate the analyses used in Net Promoter research and (2) compares Reichheld and colleagues' findings with the American Customer Satisfaction Index. Using industries Reichheld cites as exemplars of Net Promoter, the research fails to replicate his assertions regarding the "clear superiority" of Net Promoter compared with other measures in those industries.

n December 2003, noted loyalty consultant Fred Reichheld introduced a new loyalty metric, Net Promoter. ${ }^{1}$

Reichheld states that compared with other survey-based questions asked of customers, the Net Promoter score "is the best predictor of growth" (Reichheld 2006d) and further asserts that it is "the one number you need to grow" (Reichheld 2003, p. 54).

Although the appropriateness of this particular word-ofmouth metric has sparked considerable debate (Grisaffe 2004; Keiningham et al. 2005, pp. 98-101; Marketing Week 2006), BusinessWeek wryly notes, "as academics debate the details, managers are putting the [Net Promoter] scores into practice" (McGregor 2006, p. 94). Indeed, executives from some of the world's most prestigious firms have wholeheartedly adopted Net Promoter as the gauge of their firms' efforts to improve customer loyalty. As a recent cover story in Advertising Age reports (Creamer 2006, p. 1),

Less than three years after its inception, one of the most provocative marketing ideas since "The Tipping Point" is, well, hitting a tipping point. [General Electric], American Express, and Microsoft have all adopted the metric... The so-called Net Promoter Score is even being reported to investors.

${ }^{1}$ Net Promoter is a metric derived from survey responses to a recommend likelihood question. Respondents who provide a rating of 9-10 are classified as "promoters"; respondents who provide a rating of 6 or lower are classified as "detractors." Net Promoter is calculated by subtracting the proportion of a firm's detractors from its proportion of promoters (i.e., Net Promoter $=$ promoters - detractors).

Timothy L. Keiningham is Senior Vice President and Head of Consulting, IPSOS Loyalty (e-mail: tim.keiningham@ipsos-na.com). Bruce Cooil is Professor of Management, Owen Graduate School of Management, Vanderbilt University (e-mail: bruce.cooil@owen.vanderbilt.edu). Tor Wallin Andreassen is Professor of Marketing, Department of Marketing, Norwegian School of Management (e-mail: tor.w.andreassen@bi.no). Lerzan Aksoy is Assistant Professor of Marketing, College of Administrative Sciences and Economics, Koç University (e-mail: laksoy@ku.edu.tr).

To read and contribute to reader and author dialogue on $\mathrm{JM}$, visit http://www.marketingpower.com/jmblog.
It would be difficult to overstate the impact of Net Promoter on management. The following quotations from senior corporate executives offer a glimpse of the importance they place on this metric:

The last step is how we measure success, and this is something we've taken across the company called Net Promoter Score.... We're doing it in commercial finance, consumer finance, healthcare, $\mathrm{NBCU}$, every business.... [I]t's not just a kind of a metric for the sake of having a metric. It gets embedded into the culture in terms of how we interface with customers. (Jeffrey Immelt [2005], chairman and chief executive officer, General Electric)

We will focus our organization on what we call Net Promoter score, which goes much beyond the pure customer satisfaction index. (René Obermann [2005], chief executive officer, T-Mobile International AG)

So what's driving growth?... [W]e measure the customer experience using a system called Net Promoter. The higher the score, the more customers are delighted with the product and service experience and would recommend it to a friend.... [I]t's all about Net Promoter. (Steve Bennett [2005], president and chief executive officer, Intuit)

The average U.S. company has net promoter scores of between 5 and 10 . We, on very early reads, believe that we have scores sort of in the 40-45 range, which certainly would be a point that [is] quite acceptable. (Glenn Renwick [2006], president and chief executive officer, The Progressive Corporation)

There's a book that has really impressed me by Fred Reichheld ... called The Ultimate Question that seems quite plausible. And it's that you count your net promoters. (David Chidester [2006], senior vice president of finance, Overstock.com)

All companies should ask their customers what Fred [Reichheld] calls "the ultimate question." (Ken Chenault [quoted in Reichheld 2006c], chairman and chief executive officer, American Express)

As these executives' statements show, the Net Promoter metric has been adopted by some of the world's most wellrespected firms. Jack Welch, the former chairman of Gen- 
eral Electric, in an article he coauthored titled "Dialing for Growth," called Net Promoter an "up-and-coming management concept" (Welch and Welch 2006). A notable example of its acceptance is Harvard Business Online, which now surveys its customers by asking only two questions:

1. How likely are you to recommend Harvard Business Online to a friend or colleague? $(0=$ "not at all likely," and $10=$ "extremely likely"), and

2. What is your primary reason for your rating in Question 1?

The foundation of the widespread adoption of Net Promoter lies in its underlying research. For example, an article on Paul Stobart, managing director of the software firm Sage (U.K.) Limited, notes (Cree 2005, p. 51):

By way of explanation, [Stobart] launches into a lengthy exposition on Reichheld's Net Promoter Primer (NPP) theory, complete with diagrams. The lesson is long, but the theory is simple-if more people are champions for your service or product than are neutral or detractors of it, your company will grow, and vice versa. It's backed up by Reichheld's research among 4000 companies, which showed it to be 100 percent accurate in determining whether a company grew or shrank.

To date, however, the evidence regarding the relationship between the Net Promoter metric and firm revenue growth (the linkage reported in Reichheld [2003] and Satmetrix [2004]) has not been subjected to rigorous scientific scrutiny and peer review. Indeed, no researchers have attempted to replicate the research methodology.

The only longitudinal analysis attempting to examine the relationship between Net Promoter and business outcomes is that of Morgan and Rego (2006), who use data collected for the American Customer Satisfaction Index (ACSI). Unfortunately, the data used and the calculation itself differ substantially from that which Reichheld (2003) and Satmetrix (2004) advocate and test. Furthermore, Morgan and Rego appear to have significantly misunderstood the data fields from which they calculated Net Promoter (Keiningham et al. 2007). As a result, Net Promoter was not actually examined. Therefore, conclusions regarding the effectiveness of Net Promoter on business performance cannot be accurately made from that study.

The current research fills this void by providing the first cross-industry, longitudinal examination of the association between Net Promoter and firm revenue growth, and it attempts to replicate Reichheld's $(2003,2006 \mathrm{c})$ and Satmetrix's (2004) methodology. The data we used to investigate the proposed relationships consist of 21 firms tracked by the Norwegian Customer Satisfaction Barometer (NCSB), representing 15,500-plus customer interviews; periods for the firms under investigation ranged from two to four years. In addition, we replicated and tested a subset of Reichheld's (2006c) data.

\section{Theoretical Background}

\section{Word of Mouth}

There is a great deal of anecdotal evidence that word of mouth can play a significant role in a firm's sales and marketing efforts. For example, the success of Anita Diamant's novel The Red Tent (English 2000) and the movie The Blair
Witch Project (Quinn 1999) are widely attributed to wordof-mouth campaigns.

Although a positive relationship between word of mouth and sales is usually presumed, early research shows that the linkage may be more complex. In a study of the effect of word of mouth on television viewing, Godes and Mayzlin (2004a, p. 558) "could not find a consistent relationship between the volume of [word of mouth] and future television ratings." In addition, in a study of a national U.S. retailer, Godes and Mayzlin (2004b) find that the expected additional sales resulting from the word-of-mouth activities of loyal customers did not create anticipated additional sales (though word of mouth from nonloyal customers resulted in increased sales; sea also Yu 2005).

The general consensus is that word of mouth can have a major impact on consumers' responses to a product (Arndt 1967; Danaher and Rust 1996; Herr, Kardes, and Kim 1991; Wangenheim and Bayón 2004). For example, Rust, Zeithaml, and Lemon (2000, p. 46) observe that "the effect [of word of mouth] is notoriously hard to measure, but it is frequently significantly large."

To date, only a small number of researchers have proposed methods for calculating the value of word-of-mouth referrals (Helm 2006; Hogan, Lemon, and Libai 2004; Wangenheim and Bayón 2004). Furthermore, there is no peerreviewed research that longitudinally examines the relationship between word-of-mouth activity and firm-level financial outcomes (e.g., revenue, profits) across multiple industries. This has caused some eminent researchers (Danaher and Rust 1996; Godes and Mayzlin 2004b; Zeithaml 2000) to call for additional research into this relationship.

\section{Net Promoter}

Most managers became aware of Net Promoter after the release of a 2003 Harvard Business Review article titled "The One Number You Need to Grow." The overarching message of the article is that measurement of customer satisfaction and customer retention does not help firms achieve growth; instead, word of mouth is the metric that is linked to growth. However, the word-of-mouth metric must be designed in a particular way to calculate a Net Promoter score (Reichheld 2003; Word of Mouth Marketing Association [WOMMA] 2005). First, survey respondents are asked to rate their likelihood of recommending a company. Second, the proportion of respondents rating the firm a 6 or less (called "detractors") is subtracted from the proportion of respondents rating the firm a 9 or 10 (called "promoters"); this difference represents a firm's Net Promoter score.

The article cites research conducted by the firm Satmetrix (in conjunction with Bain \& Company and Reichheld) beginning in 2001 on "more than 400 companies in more than a dozen industries" as evidence of the superior power of this metric in predicting growth relative to other survey questions (Reichheld 2003, p. 51). Satmetrix (2004) subsequently provided additional detail on the analysis. Although data from customers of 400-plus companies were collected, inclusion in the actual analysis was limited to firms that met specific criteria. As a result, "over 50 companies were included across a dozen targeted industries" (Sat- 
metrix 2004). Satmetrix describes the analysis and results as follows: "Correlations were computed tying ... Net Promoter to each company's revenue growth rate for each targeted industry. [Thirty-three] correlation coefficients were then examined in terms of their absolute magnitude and level of significance to determine whether either of the two types of loyalty percentages links to corporate financial growth."

Several highly visible publications have appeared regarding Net Promoter, including an article in MIT Sloan Management Review (Reichheld 2006a) and a Wall Street Journal (2006) number-one best-selling business book, The Ultimate Question (Reichheld 2006c). In addition, numerous trade journal articles have featured Net Promoter (e.g., McGregor 2006; Morris 2006).

The primary message is that Net Promoter is the "single most reliable indicator of a company's ability to grow" (Netpromoter.com 2006). Furthermore, it is reported that Net Promoter "yields slightly less accurate predictions for the behavior of individual customers, but a far more accurate estimate of growth for the entire business" than models consisting of data from multiple survey items to predict firm growth (Reichheld 2006b).

The rates of growth attributed to changes in Net Promoter scores are impressive. Net Promoter leaders are said to "outgrow their competitors in most industries by an average of 2.5 times" (Fry 2006). It is also reported that a 12point increase in Net Promoter scores leads to a doubling of a company's growth rate on average (Marketing Week 2006; Reichheld 2006c, p. 43).

Thus far, however, there are only two non-Reichheld/ Satmetrix studies of which we are aware that have been designed specifically to test the predictive capability of the Net Promoter metric. One study was conducted by The Listening Company in conjunction with the London School of Economics (Marsden, Samson, and Upton 2005a, b). This study examines the relationship between Net Promoter levels collected in 2005 and compares them with firm growth rates for 2003-2004. The study reports a Pearson correlation of .484 when examining the relationship across the entire data set. Marsden, Samson, and Upton (2005a, p. 5) also report "a 7-point increase in the net promoter score correlated with a $1 \%$ increase in growth (1-point increase = $.147 \%$ more growth)." However, this study (1) relied on cross-sectional Net Promoter data and (2) linked Net Promoter to prior period revenue growth rates.

Morgan and Rego (2006) examine the longitudinal impact of various customer satisfaction and loyalty metrics in predicting business performance. They labeled one such metric "Net Promoter" and found that their calculation had no predictive value. As we noted previously, however, the data used and the calculation itself differ substantially from that which Reichheld (2003) and Satmetrix (2004) advocate and test. Furthermore, it appears that Morgan and Rego misunderstood the data fields from which they calculated Net Promoter (Keiningham et al. 2007). As a result, they do not actually examine Net Promoter. Therefore, conclusions regarding the effectiveness of the Net Promoter metric advocated by Reichheld (2003) on business performance cannot be made from Morgan and Rego's study.

\section{Research Objectives}

The purpose of this study is to examine the research and findings regarding Net Promoter (Reichheld 2003; Satmetrix 2004). In particular, we attempt to replicate these findings using a methodology that corresponds to that which Reichheld $(2003,2006 \mathrm{c})$ and Satmetrix (2004) use. To date, no longitudinal, peer-reviewed, cross-industry examinations have been conducted on this specific Net Promoter metric. Therefore, rather than establish a set of theory-based hypotheses, as is common in most scientific investigations, we test the overarching claim regarding Net Promoter-namely, that Net Promoter is the "single most reliable indicator of a company's ability to grow" (Netpromoter.com 2006).

\section{Methodology}

\section{Data Collection and Measurement}

The NCSB provided data on intention to recommend, overall satisfaction, and repurchase intentions. In addition, it provided an NCSB satisfaction index score. ${ }^{2}$

The NCSB was created in 1994-1995 to uncover the degree of satisfaction with various services by interviewing defined companies' existing customers. The companies included in the NCSB are all major competitors in a wide variety of service industries that are important to households. The companies surveyed in each industry are the firms with the largest market share. Cumulative shares are approximately $70 \%$.

The NCSB is based on findings from a national probability sample of households, in which there are approximately 16,000 completed telephone interviews pertaining to the measured companies. For the companies included in the study, interviews were conducted with 100-200 of their existing customers. To be eligible for an interview, a prospective respondent must qualify as the purchaser of specific services within defined periods. Thus, the definition of "customer" in the NCSB is an individual chosen randomly from a large universe of potential buyers who qualify by recent experience as the purchaser or consumer of one service of one specific company that supplies household consumers in Norway.

Unlike most data collection procedures for customer satisfaction, the NCSB identifies customers from the universe of purchasers and then identifies the company from which the customer purchased or consumed rather than starting from an identified company and its lists of customers. If a respondent qualified as a recent purchaser or consumer of a service, he or she was asked if this service came from the list of the companies being measured. If not, the interview was terminated. Each respondent was interviewed for only one service.

The NCSB, with some adjustments, is based on Fornell's work in Sweden and the United States. The theoretical foundation for these barometers is documented in the

\footnotetext{
2It our understanding that similar data from the ACSI are not available; a question about intention to recommend similar to that which Reichheld advocates has only recently been asked of a subset of firms tracked.
} 
work of Johnson and Fornell (1991), Fornell (1992), Fornell and Johnson (1993), and Fornell and colleagues (1996). For an update on the development of national satisfaction index models, see Johnson and colleagues (2001).

A subset of firms studied in the NCSB was asked questions about (1) intention to recommend, (2) overall satisfaction, and (3) repurchase intention. We included only firms for which respondents were asked these three questions for two or more consecutive years and for which firm revenue data could be obtained in the analysis. In total, 21 firms (representing 15,500-plus customer interviews) met these criteria.

We derived a Net Promoter score on the basis of responses to the question, "How likely or unlikely is it that you would recommend [Company $\mathrm{x}$ ] if a friend or business relation asked for your advice" ("very high probability/very low probability")? Because the data from the NCSB use a ten-point scale (1-10), we subtracted the percentage of respondents rating 1-6 from the percentage rating 9-10.

We also created ten other commonly used satisfaction/ loyalty metrics for the analysis: the NCSB score, overall satisfaction (mean, top box, and top two box), repurchase intention (mean, top box, and top two box), and recommend intention (mean, top box, and top two box).

\section{Replication of Reichheld's and Satmetrix's Methodology}

As we noted previously, Reichheld's (2003) and Satmetrix's (2004) research methodology consisted of examining the correlation between Net Promoter levels and a company's revenue growth rate for each industry examined. Specifically,

1. A mean Net Promoter score for each firm was computed (note that only two years of data were collected for each firm in Reichheld's and Satmetrix's analyses);

2. An average revenue growth rate, which included the two years for which Net Promoter was calculated and an additional prior year (i.e., three-year growth rates), was computed; and

3. Correlation coefficients were calculated for each industry under investigation.

It is important to remember that this research comprised "over 50 companies ... across a dozen targeted industries" (Satmetrix 2004). In the Harvard Business Review article that introduced Net Promoter, charts for three of the industries examined were presented; the sample sizes (in terms of number of firms) were three, five, and ten (Reichheld 2003). This would mean that the sample sizes for each of the remaining nine industries were approximately 3.6 on average (i.e., $[50-(3+5+10)] / 9=3.56)$. Therefore, industry sample sizes were small.

Although researchers can dispute the appropriateness of this methodology, it is the methodology on which Net Promoter is founded. Therefore, in testing the claims associated with Net Promoter, it is imperative to examine the robustness of the research on which these claims are based.

Our initial investigation is identical to that of Reichheld (2003) and Satmetrix (2004), with one important difference: the periods under investigation. In Reichheld's analysis, three-year average growth rates (1999-2002) and two-year average Net Promoter scores (2001-2002) were used. This means that Net Promoter was tied to past growth rates (as opposed to future growth rates). As a result, the data do not help identify whether Net Promoter levels are linked to current changes in revenue growth. This is an important consideration because as Godes and Mayzlin (2004b, p. 545) note, "word of mouth is not exogenous. While the mapping from word of mouth to future sales is of great interest to the firm, we must also recognize that word of mouth is an outcome of past sales." Therefore, our research uses identical time frames when examining the correlation between Net Promoter and revenue growth rates.

In keeping with Reichheld's (2003) and Satmetrix's (2004) methodology, we grouped the firms in our analysis by industry and examined them separately. We determined industry classification using the North American Industrial Classification System (NAICS). Industry groupings were based on the first three digits of the NAICS; these groupings correspond to the same groupings that would have occurred if Fama and French's (1997) industrial groupings were used. Note that in all but one industry (transportation), industry groupings corresponded to the complete six-digit NAICS code.

In total, five industries (representing 17 of the 21 firms in our data file) contained the threshold minimum number of firms for which Reichheld (2003) and Satmetrix (2004) conducted their analysis. These industries are banking, gasoline stations (with convenience stores), home furnishings retailers, security systems, and transportation (local/ suburban transit).

Table 1 presents the industry-level correlations between firms' growth rates (i.e., relative change in revenue) and Net Promoter and other commonly used satisfaction/loyalty metrics for the various periods available. The most obvious finding when examining this table is that in light of the data under investigation, Net Promoter in no way would be categorized as the "single most reliable indicator of a company's ability to grow" (Netpromoter.com 2006). Indeed, there is no real indication that average levels of any of the satisfaction/loyalty metrics in Table 1 are significantly correlated with the relative change in revenue within the respective industry. We report $p$ values only when correlations were based on at least five observations.

The pooled results in Table 1 are for correlations between annual relative change in revenue and the average of each satisfaction/loyalty metric for the corresponding period, pooled across successive periods and across all firms within industry (these correlations are adjusted for firm effects). Note that this pooling of annual results is for the four annual periods between 2001 and 2005 in the banking industry and for the three annual periods from 2000 to 2003 in the retail gasoline industry. Nevertheless, for comparison, Table 1 also reports the results for all one- and twoyear periods, as indicated by the different "Year Start" and "Year End" dates.

In the retail gasoline industry, annual relative change in revenue has significant autocorrelation (lag 1), and we adjust these reported correlations for this effect. None of the unadjusted correlations were significant (in every case, $p>$ .35). In banking, lagged relative change in revenue has no 


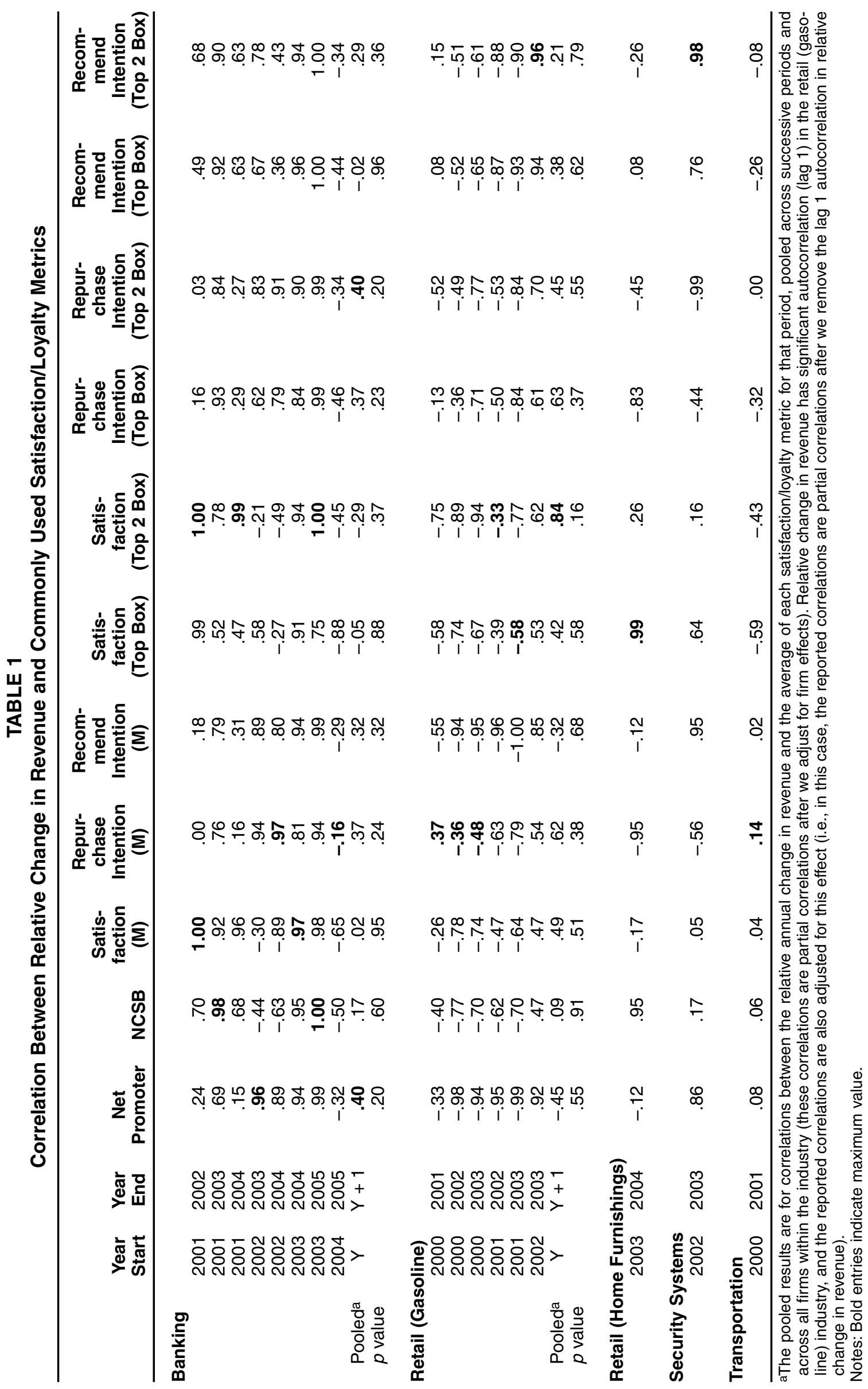


incremental value in any of the regressions used to calculate correlations (in every case, $p>.3$ ), and we did not make this additional adjustment. The residuals from these regressions are never significantly nonrandom (in every case, $p>.15$; in all but one case, $p>.3$ ).

Table 1 also points to the inherent difficulty of predicting firm revenue growth within an industry on the basis of a single attitude-based metric. Nevertheless, we would expect that a serious, longer-term, longitudinal study would show that changes in satisfaction/loyalty metrics are important predictors of relative changes in revenue within firms.

\section{Models Based on Multiple Satisfaction/Loyalty Metrics}

We also conducted best-subsets analyses in which we considered all 11 satisfaction/loyalty metrics in Table 1 candidate predictors for relative annual change in revenue, along with fixed industry effects (in which we represented industries as indicator variables). The best scientific model (in terms of the Bayesian information criterion; see Schwarz 1978) did not include any of these metrics; it included only the most significant industry effects. ${ }^{3}$

\section{Comparing the ACSI and Net Promoter}

In addition to the NCSB examination we reported previously, we attempted to analyze the Net Promoter and firm growth data used by Reichheld (2003) and Satmetrix (2004) with other variables used in their investigation. Without access to their raw data, it is impossible to compare Net Promoter with the other satisfaction/loyalty metrics collected in their surveys. However, there is an opportunity to compare Net Promoter with the ACSI, a metric that was investigated and found not to correlate with growth (Reichheld 2004).

In the Harvard Business Review article that introduced Net Promoter (Reichheld 2003, p. 49), in the book The Ultimate Question (Reichheld 2006c, pp. 84-86), and in presentations regarding Net Promoter (Reichheld 2004), the ACSI is specifically mentioned as not being linked to firm growth. In The Ultimate Question, Reichheld (2006c, p. 86) argues that the ACSI does not yield much insight into loyalty or growth, noting that "investors rarely waste money on standard satisfaction surveys" as a result. Similarly, in the Harvard Business Review article, Reichheld (2003, p. 49) states,

\footnotetext{
${ }^{3}$ Note that because the NCSB data are limited to firms with the largest market share (as is the ACSI), there is a possible restriction of range in the measures used. As a result, variability may be lost that might have been otherwise present if other firms had been included. Despite this restriction, however, we believe that this is similar in terms of firm inclusion to the methodology that Reichheld (2003) and Satmetrix (2004) employ. Analysis of the industry-level charts that Reichheld $(2003,2006 c)$ and Satmetrix report shows that the vast majority of firms in their industry-level analyses constitute high-relative-market-share firms; as we noted previously, the sample sizes that Reichheld (2003) and Satmetrix use are very small and thus, in most cases that we are aware of, constitute relatively large-market-share firms for their respective industries.
}

Our research indicates that satisfaction lacks a consistently demonstrable connection to actual customer behavior and growth. This finding is borne out by the short shrift that investors give to such reports as the [ACSI]. The ACSI, published quarterly in The Wall Street Journal, reflects customer satisfaction ratings of some 200 U.S. companies. In general, it is difficult to discern a strong correlation between high customer satisfaction scores and outstanding sales growth.

Furthermore, in a Web-based presentation, Reichheld (2004) states that a "Bain team looked at the correlation between growth and customer satisfaction, and found there is none." A scatter diagram was shown with the x-axis labeled "[ACSI] annual growth" and the y-axis labeled "Sales annual growth." The R-square reported was .00, indicating no correlation.

This finding is in direct contradiction to several Journal of Marketing articles that specifically examine the relationship between the ACSI and business results. For example,

-Anderson, Fornell, and Mazvancheryl (2004) find a positive association between the ACSI and Tobin's q (the ratio of a firm's market value to the replacement cost of its assets [Tobin 1969]), the ratio of price to book value, and equity prices.

- Gruca and Rego (2005) use ACSI and COMPUSTAT data and find that satisfaction creates shareholder value by increasing future cash flow growth and reducing its variability.

-Fornell and colleagues (2006) find that firms that performed better in terms of their ACSI scores also performed significantly in terms of market returns.

Given that a Bain team examined the relationship between the ACSI and growth, it appears reasonable to presume that a comparison of the ACSI and Net Promoter was conducted. Fortunately, actual data reported in The Ultimate Question (Reichheld 2006c) offer such an opportunity. The Appendix to the book presents charts for six industries to demonstrate the relationship between Net Promoter and firm growth (four U.S. industries, one U.K. industry, and one Korean industry). Three of the U.S. industries are also tracked by the ACSI: airlines, life insurance, and computers. To present a fair comparison between the ACSI and Net Promoter, we replicated the data. On the basis of their scatterplots, we reconstructed data that showed the relationship between Net Promoter scores and growth (Reichheld 2006c, pp. 192-94).

To ensure accuracy, we enlarged and scanned the tables and imported the corresponding graphics into a charting software package in which they were used as background images. Over the images, we created a new scatterplot using the exact dimensions of the scanned image. We input data until each point in the chart corresponded to the scanned images. As a final check of the data, we compared the coefficient of determination $\left(\mathrm{R}^{2}\right)$ of the recreated data with the reported R-square. All R-square values were the same, indicating a successful replication of the data.

Although the number of charts reported limit the scope of this investigation, Reichheld specifically selected these data sets to demonstrate the linkage between Net Promoter and growth. As such, they should reveal relationships in which 
Net Promoter is a superior predictor of growth to other metrics.

Figure 1 compares the original charts reported (Reichheld 2006c, pp. 192-93), showing the relationship between Net Promoter and growth and the relationship between the ACSI scores and growth. Note that we used the same firmlevel growth rates reported for each comparative chart and mean ACSI scores for the same years for which the Net Promoter scores were calculated.

The most obvious initial finding was the overwhelming similarity between the charts being compared. Given that the ACSI had been specifically noted as having no correlation to growth (Reichheld 2004), we expected dramatically different results, particularly because these industries were selected as exemplars of the relationship between Net Promoter and growth. Even more startling, however, in two of the three cases, the R-square of the ACSI-growth relationship is higher than that for the Net Promoter-growth relationship. These results show that Net Promoter cannot be called the better predictor of growth in relation to customer satisfaction for the industries under investigation.

The findings are even more profound when put in the context of Reichheld's (2003) and Satmetrix's (2004) total analyses. As we noted previously, Satmetrix reports, "In total, over 50 companies were included across a dozen target industries, such as airlines, package delivery, and life insurance." Therefore, our analysis comprises $25 \%$ of total industries (i.e., 3/12) and approximately $40 \%$ of firms used in Reichheld's and Satmetrix's industry-level analyses.

Furthermore, Reichheld (2003) and Satmetrix (2004) acknowledge that some of the 12 industries they examined do not have significant, positive correlations between Net Promoter and growth. They do not provide the exact number of these industries; Satmetrix states that the "analysis revealed significant correlations for a majority of the targeted industries."

Similarly, Reichheld (2003, pp. 51-52) acknowledges that Net Promoter was not the best predictor for all industries: "The 'would-recommend' question wasn't the best predictor of growth in every case ... in database software, or computer systems, for instance,... industries dominated by monopolies or near monopolies, [and] ... in the local telephone and cable [television] businesses." It is unclear whether these industries are included among the 12 industries described as the sample universe of industries used in the analysis. If not, there are clearly selection bias issues in the analysis. If they are, this implies that Net Promoter was determined not to be the most appropriate metric for $33 \%$ the industries examined (i.e., 4 industries [database software, computer systems, local telephone, and cable television] of the 12). With the additional knowledge that the ACSI resulted in a higher R-square than Net Promoter for 2 of the 3 industries we were able to replicate, this implies that in $50 \%$ of the industries in which Net Promoter was examined, Net Promoter could not be classified as the best predictor. The remaining U.S. industries are either unknown (and therefore cannot yet be tested) or do not have equivalent ACSI data for comparison (e.g., car rentals, Internet service providers). In the case of Internet service providers, ACSI tracks only 2 of the 3 firms used in the Net Promoter analysis, but directionally, they appear to align with Reichheld's (2003) and Satmetrix's (2004) research (see Figure 2). ${ }^{4}$

\section{Discussion and Implications}

We find no support for the claim that Net Promoter is the "single most reliable indicator of a company's ability to grow" (Netpromoter.com 2006; Nicks 2006). Although we do not have access to the raw data from which these claims were made, we were able to compare some of the exemplar cases of Net Promoter with the ACSI, which Reichheld (2004) reports does not correlate with growth. Instead, we found that when making "apples-to-apples" comparisons, Net Promoter does not perform better than the ACSI for the data under investigation.

Reichheld (2006b) acknowledges "imperfections" in the analytics that were used to support Net Promoter:

\begin{abstract}
All we did was quantify this common sense in a way that made sense to business leaders - the target audience for my book. These practical leaders have little interest in advanced statistical methods. Frankly, we see little value in continued debate about cause versus correlation, timeframes, or statistical methods.
\end{abstract}

Unfortunately, the statistics matter. As the previously reported comments by Paul Stobart (see Cree 2005, p. 51) demonstrate, executives believe that Net Promoter is based on solid analytic research. As a result, the use of Net Promoter has been widely adopted by some of the most prestigious firms in the world, and chief executive officers report Net Promoter data to analysts during their conference calls.

In addition, Net Promoter has been promoted as the only metric needed in customer surveys to manage growth (Reichheld 2003, 2006c). Ironically, our comparison of Net Promoter with the ACSI shows that Net Promoter is not superior to the ACSI for the data under investigation. Furthermore, our comparison used industries portrayed as exemplars of the relationship between Net Promoter and growth.

The clear implication is that managers have adopted the Net Promoter metric for tracking growth on the basis of the belief that solid science underpins the findings and that it is superior to other metrics. However, our research suggests that such presumptions are erroneous. The consequences are the potential misallocation of resources as a function of erroneous strategies guided by Net Promoter on firm performance, company value, and shareholder wealth.

We would be remiss in our discussion of possible causes of the differences between our findings and those of Reichheld (2003) and Satmetrix (2004) if we did not acknowledge the possibility of research bias (i.e., unknown or unacknowledged error created during the design, measurement, sampling, procedure, or choice of problem studied). Note that we examined potential factors that could have yielded different results; however, none would appear to explain the

${ }^{4}$ Note that Figures 1 and 2 represent all four U.S. industry charts used to support the relationship between Net Promoter and growth in The Ultimate Question (Reichheld 2006c). 
FIGURE 1

Comparison of Net Promoter and the ACSI for Wintel Computers, Life Insurance, and Airlines

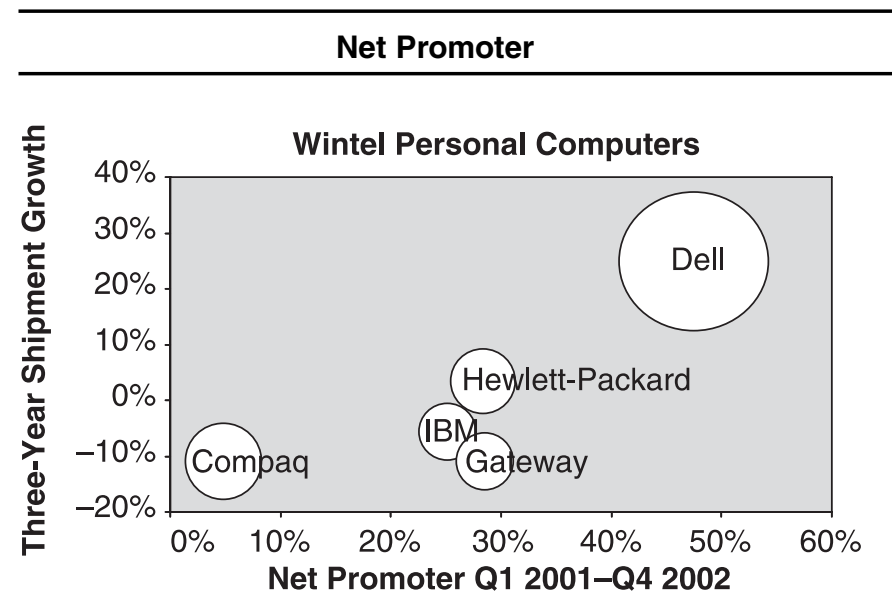

ACSI

$\mathrm{R}^{2}$ :

.68

$\mathrm{R}^{2}$ (ACSI-only companies): .70
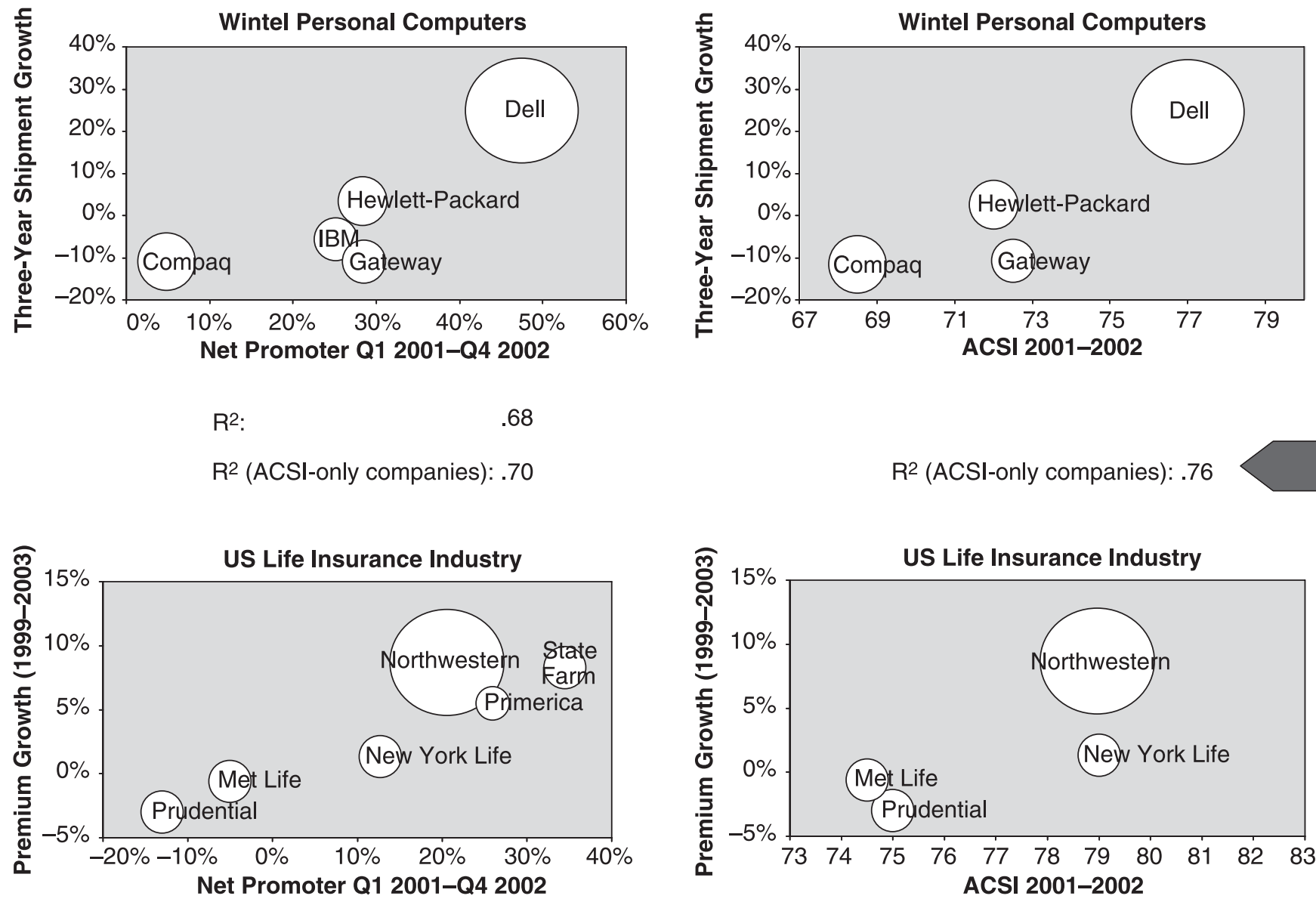

$\mathrm{R}^{2}$ :

.86

$\mathrm{R}^{2}$ (ACSI-only companies): .83

$\mathrm{R}^{2}$ (ACSI-only companies): .58
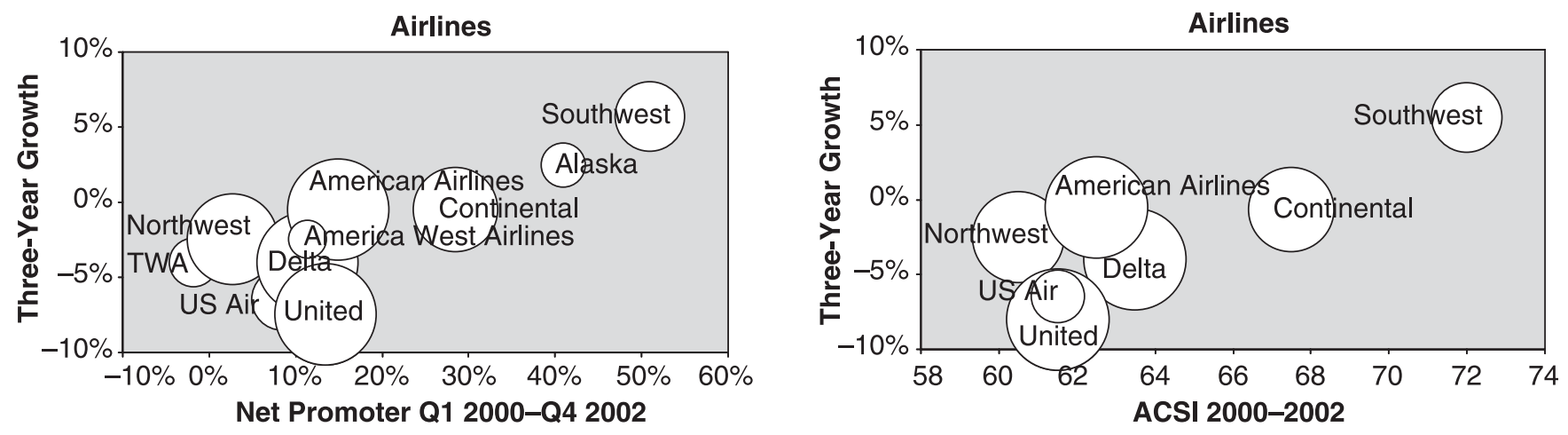

$\mathrm{R}^{2}$ :

.68

$\mathrm{R}^{2}$ (ACSI-only companies): .57

$\mathrm{R}^{2}$ (ACSI-only companies): .70

Notes: We obtained Net Promoter and growth data by reconstructing data according to their scatterplots in The Ultimate Question (Reichheld 2006c, pp. 192-93). 


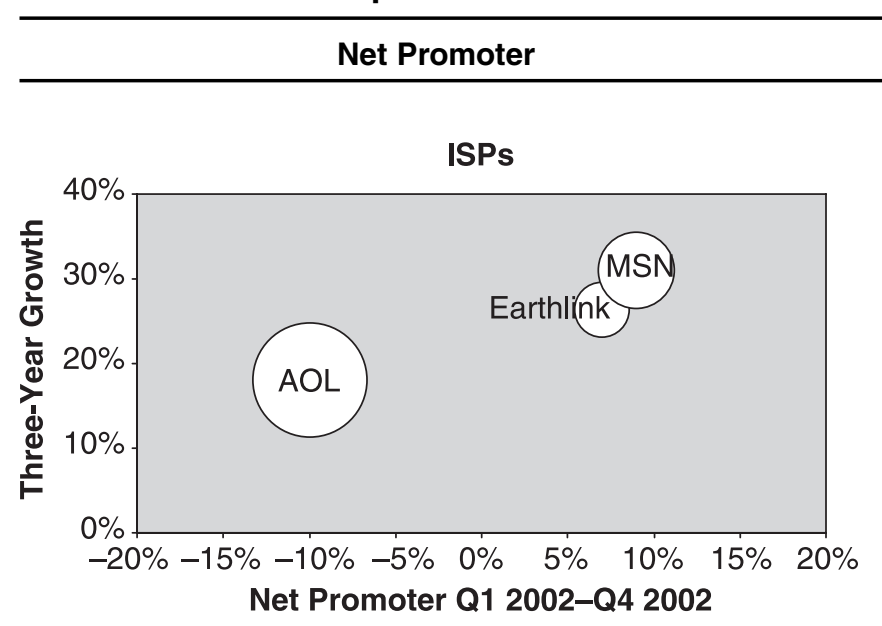

ACSI

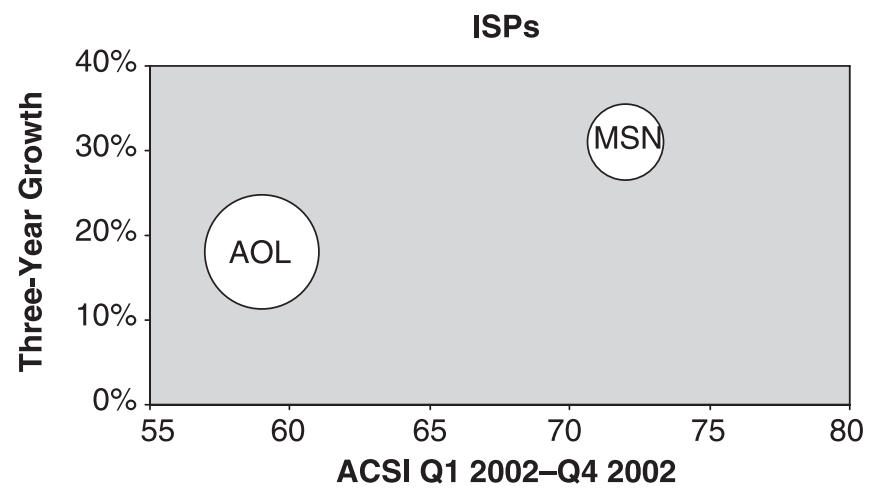

$\mathrm{R}^{2}$ :

.93

$\mathrm{R}^{2}$ (ACSI-only companies): Not available

$\mathrm{R}^{2}$ (ACSI-only companies): Not available

Notes: We obtained Net Promoter and growth data by reconstructing data according to their scatterplots in The Ultimate Question (Reichheld 2006c, p. 194)

differences between our results and those of Reichheld and Satmetrix (see the Appendix). In light of the NCSB data, it is difficult to imagine a scenario in which Net Promoter would be classified as the superior metric. In addition, our comparison of the ACSI and Net Promoter resulted in a similar conclusion.

\section{Limitations and Further Research}

Throughout this article, we have been careful to discuss the relationship between Net Promoter and changes in revenue and to avoid any suggestions of causality. This is in keeping with the methods employed; it is difficult to draw clean inferences of causality.

In addition, although we discuss the possibility of research bias in the data analytics used to support Net Promoter, this has not been proved. Only an independent, objective validation of the data used to support Reichheld's (2003) and Satmetrix's (2004) findings could conclusively prove such a bias.

Nonetheless, we believe that these results are compelling in light of the widespread use of Net Promoter by firms. Furthermore, we believe that our research demonstrates the necessity of rigorously and scientifically testing measures reported to be predictive of business outcomes before their widespread adoption (Keiningham, Vavra, and Aksoy 2006).

\section{Appendix}

Because our findings regarding the relationship between Net Promoter and revenue growth rates differ considerably from those of Reichheld (Marketing Week 2006; Reichheld
2003, 2006a, c) and Satmetrix (2004), we explore several potential causes: data quality, "would-recommend" question wording, 10- versus 11-point scale, and cultural differences. However, none appear to explain the differences between our results and those of Reichheld (2003) and Satmetrix (2004).

\section{Data Quality}

The NCSB data are based on a national probability sample of purchasers from each firm tracked. The entire NCSB process is based on a rigorous theoretical foundation (Fornell 1992; Fornell and Johnson 1993; Fornell et al. 1996; Johnson and Fornell 1991). With regard to the revenue growth rates used, all information was contained in the financial reports for each company under investigation.

According to Satmetrix (2004), data were first gathered from Satmetrix Systems's benchmarking database. Each quarter, Satmetrix gathers " 10,000 to 15,000 responses to a very brief e-mail survey that asked respondents (gathered again from public sources, not Satmetrix's internal client customer lists) to rate one or two companies with which they were familiar" (Reichheld 2003, p. 51). To qualify for inclusion in the analysis, "each company under consideration had to have a sufficient number of opt-in survey respondents to ensure accuracy and stability of their loyalty scores. In total, over 50 companies were included across a dozen targeted industries" (Satmetrix 2004). With regard to the sample size and financial metric used, Reichheld (2006a, p. 42) specifies, "We calculated Net Promoter Scores for every company that garnered at least 100 responses, then plotted each company's [Net Promoter score] against its revenue growth rate." 
The descriptions of the sampling methodologies the NCSB and Satmetrix used do not raise any obvious alarms. Although the modality differs between the two studies (outbound telephone versus e-mail), these differences would not be expected to affect significantly the relative performance of firms within their respective industries. Therefore, we believe that sample data issues are unlikely to explain the magnitude of the differences between our results and those of Reichheld (2003, 2006c) and Satmetrix (2004), particularly given that our investigation also included an examination of data reported in The Ultimate Question (Reichheld 2006c).

\section{“Would-Recommend” Question Wording}

In attempting to validate a metric, it is vital to ensure that the compared items are gauging the same construct. In the case of Net Promoter, the metric is based on consumer responses to a willingness-to-recommend survey question. As such, the question used for validation should correspond to the one under investigation. Reichheld (2003, p. 50) notes that the recommended question for measuring Net Promoter is, "How likely is it that you would recommend [company $\mathrm{x}$ ] to a friend or colleague?"

We are indeed fortunate that the NCSB question is remarkably close, particularly given its creation before Reichheld's (2003) initial article in the Harvard Business Review. The English translation (from Norwegian) is, "How likely or unlikely is it that you would recommend [Company $\mathrm{x}]$ if a friend or business relation asked for your advice?" Given the extremely close wording of the willingness-to-recommend question, we believe that question wording is unlikely to explain the magnitude of the discrepancies between our findings and those of Reichheld (2003) and Satmetrix (2004).

\section{0- Versus 11-Point Scale}

Reichheld (2003, p. 51) recommends an 11-point satisfaction scale (0-10), noting, "[W]e settled on a scale where ten means 'extremely likely,' five means neutral, and zero means 'not at all likely." "Respondents with ratings of 9 or 10 were classified as promoters. Respondents with ratings of $0-6$ were classified as detractors. The percentage of detractors was subtracted from the percentage of promoters to arrive at a Net Promoter score.

Data from the NCSB use a 10-point scale (1-10). To calculate the Net Promoter score used in that analysis, the percentage of respondents rating 1-6 was subtracted from the percentage rating 9-10.

On the basis of a review of the literature regarding rating scales and companies' actual implementation of Net Promoter, however, we do not believe that the difference between 10- and 11-point scales contributes significantly to our findings.

As Guilford (1954) noted nearly half a century ago, in terms of psychometric theory, it is advantageous to use more rather than fewer rating points because the reliability of the rating scales increases with the number of rating points. In a classic textbook in the field, Nunnally (1967, p. 22) states, "By far the bulk of the studies report increasing reliabilities up to 20 steps (although the increase from about 11 to 20 usually is small)." He also states (p. 5231), "As the number of scale steps is increased from 2 up through 20 , the increase in reliability is very rapid at first. It tends to level off at about 7, and after 11 steps, there is little gain in reliability."

As such, the reliability difference between 10- and 11point scales is shown to be small. Morrison (1972) assesses the degree to which R-square (the coefficient of determination) is lowered for different numbers of interval scales. In the case of 10- and 11-point scales, both capture $99 \%$ of the information available; the increase in R-square of using an 11-point scale rather than a 10-point scale is .0018.

Perhaps most important, the 10- and 11-point scale distinction does not appear to be relevant based on its actual implementation by advocates and users of the metric. From publicly available information, it appears that many firms using Net Promoter apply a 10-point scale (Immelt 2005; Mann 2006; Murphy 2006; QuestionnairePro 2006; Ruff 2004; WOMMA 2005). For example, Jeffrey Immelt (2005) describes General Electric's calculation of Net Promoter as follows:

[Net Promoter is] the simplest of all metrics that you can possibly have. It's a surveying tool that you take to your customers. They rate you on a scale of 1 to $10 \ldots$ A 9 and 10 is a promoter. A 1 through 6 is a detractor. You take promoters minus detractors. That gives you a Net Promoter score.

Reichheld (2006c, p. 73) features General Electric (and Immelt specifically) as an exemplar of the use of Net Promoter. Furthermore, the calculation of Net Promoter with a 10-point scale is advocated by WOMMA (2005) as part of its Basic Training newsletter. Finally, Reichheld (2006c, p. 98) writes that "other scales seem to work: Enterprise has achieved outstanding success with its 5-point scale, and eBay's well-regarded feedback system utilizes a 3-point rating system (positive, neutral, negative)."

With regard to the anchors for each of the scales, Reichheld (2003) and Satmetrix (2004) advocate using "extremely likely/not at all likely." The anchors for the NCSB data regarding the likelihood-of-recommending question are "very high probability/very low probability" (translated from Norwegian).

Given this theoretical and empirical information, we believe that the differences between the 10-point scale used by the NCSB and the 11-point scale used by Satmetrix (2004) are unlikely to explain the magnitude of the discrepancies between our findings and those reported (Marketing Week 2006; Reichheld 2003, 2006a, c; Satmetrix 2004).

Furthermore, our examination included a comparison of the Net Promoter data that Reichheld (2006c) used and firms the ACSI tracked. This examination did not confirm the reported superiority of Net Promoter as a predictor of growth.

\section{Cultural Differences}

Hofstede (1994, p. 4) defines culture as "the collective programming of the mind which distinguishes the members of one group or category of people from those of another." 
There exists a large body of marketing literature on crosscultural issues. With regard to this research, cultural differences have long been known to affect how respondents rate survey items; in particular, culture creates a form of rating scale bias.

Research has addressed rating-scale biases and crosscountry measurement equivalence. Greenleaf (1992) notes the presence of response style bias in consumer surveys and suggests a method of removing bias to increase the accuracy of survey research. Similarly, Varki and Rust (1997) propose a methodology for comparing satisfaction ratings between different firms designed to minimize the limitations of conventional analysis of variance tests. Several researches have extended measurement bias examination to include cross-country research (Iacobucci et al. 2003; Mullen 1995; Singh 1995; Steenkamp and Baumgartner 1998; Vandenberg 2002; Wong, Rindfleisch, and Burroughs 2003).

Furthermore, many cross-cultural comparisons begin with Hofstede's (1983a, b, c) dimensions of culture. Hofstede initially proposed four universal dimensions: individualism, power distance, masculinity, and uncertainty avoidance. Subsequently, Hofstede and Bond (1988) proposed a fifth dimension: the Confucian dynamic (also referred to as long-term orientation; see Hofstede 1994).

With regard to the current research, however, we believe that cultural rating-scale bias is unlikely to play a major role in examining the relationship between Net Promoter and firm revenue growth. There are several reasons for this position:

First, cultural rating-scale bias largely affects the ability to compare scores (rating levels) for different cultures or countries (e.g., equivalent absolute customer satisfaction levels may be reported differently by members of different cultures). However, we are not comparing U.S. and Norwegian Net Promoter scores. Rather, we are examining the relationship between Net Promoter and revenue growth for Norwegian firms. Although the absolute Net Promoter scores might be expected to be different, we do not expect that the relationship to growth will be dramatically different, particularly because both Norway and the United States are competitive, developed Western economies.

Second, the underlying logic behind Net Promoter is that word of mouth drives revenue growth. In a study of Europe (including Norway) and the United States, Dawar, Parker, and Price (1996) use Hofstede's cultural characteristics to examine interpersonal information exchange. They find that cultural differences help explain the focus of consumers' product information search activities but not their tendencies to share product-related opinions with others. The implication is that cultural dimensions for the countries under investigation do not affect consumers' word-of-mouth likelihood.

Net Promoter has been actively promoted and sold worldwide. Reichheld (2006c, p. 42) reports, "The pattern [of Net Promoter scores to growth] is similar in many markets outside the United States." Furthermore, the book The Ultimate Question (Reichheld 2006c, p. 183) specifically alludes to challenges to the recommended scale based on cultural differences as attempts to discredit Net Promoter. To demonstrate the global power of Net Promoter, two of the six industry charts in the book that are designed to demonstrate the relationship between Net Promoter and growth are from outside the United States; specifically, they are from the United Kingdom and Korea (Reichheld 2006c, pp. 192-94). Finally, The Ultimate Question provides a list of best and worst firms (winners and sinners) in terms of Net Promoter for the United States and the United Kingdom (Reichheld 2006c, p. 196). No cultural differences were reported between the various countries.

Third, our examination included a comparison of the Net Promoter data that Reichheld (2006c) used and firms the ACSI tracked. This examination did not confirm the reported superiority of Net Promoter as a predictor of growth.

\section{REFERENCES}

Anderson, Eugene W., Claes Fornell, and Sanal K. Mazvancheryl (2004), "Customer Satisfaction and Shareholder Value," Journal of Marketing, 68 (October), 172-85.

Arndt, J. (1967), "Word-of-Mouth Advertising and Informal Communication," in Risk Taking and Information Handling in Consumer Behavior, D.F. Cox, ed. Boston: Harvard Business School Press.

Bennett, Steve (2005), "Q3 2005 Intuit Earnings Conference Call-Final," Fair Disclosure Wire, (May 18).

Chidester, David (2006), "Q1 2006 Overstock.com Inc. Earnings Conference Call-Final," Fair Disclosure Wire, (April 28).

Creamer, Matthew (2006), "Do You Know Your Score: Your Business Rides on How Consumers Answer the One Crucial Question," Advertising Age, (July 3), 1, 24.

Cree, Richard (2005), "Paul Stobart," Director, 58 (February), 48-52.

Danaher, Peter J. and Roland T. Rust (1996), "Determining the Optimal Return on Investment for an Advertising Campaign," European Journal of Operational Research, 95 (3), 511-21.
Dawar, Niraj, Philip M. Parker, and Lydia J. Price (1996), "A Cross-Cultural Study of Interpersonal Information Exchange," Journal of International Business Studies, 27 (3), 497-516.

English, Bella (2000), "Pitching Her 'Tent' Word of Mouth, Plus Author Anita Diamant's Promotional Moxie, Make for Success," Boston Globe, (February 24), F1.

Fama, Eugene F. and Kenneth R. French (1997), "Industry Costs of Equity," Journal of Financial Economics, 43 (February), 153-93.

Fornell, Claes (1992), "A National Customer Satisfaction Barometer: The Swedish Experience," Journal of Marketing, 56 (January), 6-21.

- and Michael D. Johnson (1993), "Differentiation as a Basis for Explaining Customer Satisfaction Across Industries," Journal of Economic Psychology, 14 (4), 681-96.

- $\longrightarrow$ Eugene W. Anderson, Jaesung Cha, and Barbara Everitt Bryant (1996), "The American Customer Satisfaction Index: Nature, Purpose, and Findings," Journal of Marketing, 60 (October), 7-18. 
, Sunil Mithas, Forest V. Morgenson III, and M.S. Krishan (2006), "Customer Satisfaction and Stock Prices: High Returns, Low Risk," Journal of Marketing, 70 (January), 1-14. Fry, Elizabeth (2006), "Take Cover," CFO (Australia), (August 1), (accessed September 16, 2006), [available at http://global. factiva.com.proxy.library.vanderbilt.edu/ha/default.aspx].

Godes, David and Dina Mayzlin (2004a), "Firm-Created Word-ofMouth Communication: A Field-Based Quasi-Experiment," Harvard Business School Marketing Research Paper No. 0403 .

and - (2004b), "Using Online Conversations to Study Word-of-Mouth Communication," Marketing Science, 23 (Fall), 545-60.

Greenleaf, Eric (1992), "Improving Rating Scale Measures by Detecting and Correcting Bias Components in Some Response Styles," Journal of Marketing Research, 29 (May), 176-88.

Grisaffe, Doug (2004), "Guru Misses the Mark with 'One Number' Fallacy,” (February), (accessed February 20, 2006), [available at http://www.creatingloyalty.com/story.cfm?article_id= $656]$.

Gruca, Thomas S. and Lopo L. Rego (2005), "Customer Satisfaction, Cash Flow, and Shareholder Value," Journal of Marketing, 69 (July), 115-30.

Guilford, J. (1954), Psychometric Methods. New York: McGrawHill.

Helm, Sabrina (2006), "Calculating the Value of Customers' Referrals," Managing Service Quality, 13 (2), 124-33.

Herr, Paul M., Frank R. Kardes, and John Kim (1991), "Effects of Word-of-Mouth and Product-Attribute Information on Persuasion: An Accessibility-Diagnosticity Perspective," Journal of Consumer Research, 17 (March), 454-62.

Hofstede, Geert (1983a), "The Cultural Relativity of Organizational Practices and Theories," Journal of International Business Studies, 14 (Fall), 75-89.

(1983b), "Dimensions of National Cultures in Fifty Countries and Three Regions," in Explications in Cross-Cultural Psychology, J.B. Deregowski, S. Dziurawiec, and R.C. Annis, eds. Lisse, Switzerland: Swets \& Zeitlinger, 335-55.

(1983c), "National Cultures in Four Dimensions: A Research-Based Theory of Cultural Differences Among Nations," International Studies of Management \& Organization, 13 (Spring-Summer), 46-74.

(1994), "Management Scientists Are Human," Management Science, 40 (January), 4-13.

- and Michael Harris Bond (1988), "The Confucius Connection: From Cultural Roots to Economic Growth," Organizational Dynamics, 16 (Spring), 4-21.

Hogan, John E., Katherine N. Lemon, and Barak Libai (2004), "Quantifying the Ripple: Word-of-Mouth and Advertising Effectiveness," Journal of Advertising Research, 44 (September-October), 271-80.

Iacobucci, Dawn, Doug Grisaffe, Adam Duhachek, and Alberto Marcati (2003), "FAC-SEM: A Methodology for Modeling Factorial Structural Equations Models, Applied to CrossCultural and Cross-Industry Drivers of Customer Evaluations," Journal of Service Research, 6 (August), 3-23.

Immelt, Jeffrey (2005), "GE Annual Outlook Meeting-Final," Fair Disclosure Wire, (December 13).

Johnson, Michael D. and Claes Fornell (1991), "A Framework for Comparing Customer Satisfaction Across Individuals and Product Categories," Journal of Economic Psychology, 12 (2), 267-86.

- Anders Gustafsson, Tor Wallin Andreassen, Line Lervik, and Jaesung Cha (2001), "The Evolution and Future of National Customer Satisfaction Index Models," Journal of Economic Psychology, 22 (April), 217-45.

Keiningham, Timothy L., Lerzan Aksoy, Bruce Cooil, and Tor W. Andreassen (2007), "Commentary on 'The Value of Different
Customer Satisfaction and Loyalty Metrics in Predicting Business Performance,'” Marketing Science, forthcoming.

, Terry G. Vavra, and Lerzan Aksoy (2006), "Managing Through Rose-Colored Glasses," MIT Sloan Management Review, 48 (1), 15-18.

- - - Myths: Hyped Strategies That Will Put You Out of Business, and Proven Tactics That Really Work. Hoboken, NJ: John Wiley \& Sons.

Mann, Joseph (2006), "Customer Satisfaction Rates Are Like So Last Week," Marketing and Demand Creation ROI, (March 12), (accessed March 27, 2007), [available at http://marketingroi.blogspot.com/2006/03/customer-satisfaction-rates-arelike.html].

Marketing Week (2006), "Ultimate Question Twitching on Loyalty Guru Reichheld's Lips," (January 26), 28.

Marsden, Paul, Alain Samson, and Neville Upton (2005a), "Advocacy Drives Growth: Customer Advocacy Drives UK Business Growth," The Listening Company white paper, (accessed March 1, 2007), [available at http://www.listening.co.uk/ content/pages/news/items/advocacy_drives_growth.shtml].

- and (2005b), "Research: Advocacy Drives Growth: Customer Advocacy Drives UK Business Growth," Brand Strategy, (December), 45-48.

McGregor, Jena (2006), "Would You Recommend Us?" BusinessWeek, (January 30), 94.

Morgan, Neil A. and Lopo Leottte do Rego (2006), "The Value of Different Customer Satisfaction and Loyalty Metrics in Predicting Business Performance," Marketing Science, 25 (5), 426-39.

Morris, Betsy (2006), "New Rule: The Customer Is King," Fortune, (July 11), 70.

Morrison, Donald G. (1972), "Regressions with Discrete Dependent Variables: The Effect on $\mathrm{R}^{2}$," Journal of Marketing Research, 9 (August), 338-40.

Mullen, Michael R. (1995), "Diagnosing Measurement Equivalence in Cross-National Research," Journal of International Business Studies, 26 (3), 573-96.

Murphy, Mark (2006), "Growing Your Laboratory Business Is Like Gardening," JDT Unbound, (February), (accessed March 1, 2007), [available at http://www.nadl.org/jdtunbound/ murphy0206.htm].

Netpromoter.com (2006), "What Is Net Promoter?" (accessed September 16, 2006), [available at http://www.netpromoter.com/ netpromoter/index.php].

Nicks, Stephen (2006), "What Not to Do with Net Promoter," BusinessWeek Online, (August 1), (accessed March 1, 2007), [available at http://www.businessweek.com/smallbiz/content/ jul2006/sb20060731_349936.htm?campaign_id=rss_null].

Nunnally, Jum C. (1967), Psychometric Theory. New York: McGraw-Hill.

Obermann, René (2005), "Q3 2005 Deutsche Telekom Earnings Conference Call-Final," Fair Disclosure Wire, (November 9).

QuestionnairePro (2006), "Net Promoter Score: Scoring Logic," (accessed March 1, 2007), [available at http://www. questionpro.com/help/265-inline.html].

Quinn, Judy (1999), "Blair Witch: Hot Project for NAL, Too," Publishers Weekly, (August 9), 210-11.

Reichheld, Frederick F. (2003), "The One Number You Need to Grow," Harvard Business Review, 81 (December), 46-54.

- (2004), "Net Promoters," Bain \& Company Web-based presentation (slide 4), (February), (accessed April 18, 2007), [available at http://resultsbrief.bain.com/videos/0402/main. html].

(2006a), "The Microeconomics of Customer Relationships," MIT Sloan Management Review, 47 (Winter), 73-78. 
(2006b), "Questions About NPS—and Some Answers," (accessed March 1, 2007), [available at http://netpromoter. typepad.com/fred_reichheld/2006/07/questions_about.html].

(2006c), The Ultimate Question: Driving Good Profits and True Growth. Boston: Harvard Business School Press. (2006d), "The Ultimate Question, with Fred Reichheld," a MarketingProfs Virtual Seminar, (July 11, 2006), (accessed March 15, 2007), [available at http://www.marketingprofs. com].

Renwick, Glenn (2006), "The Progressive Corporation 2006 Investor Relations Meeting Conference Call-Final," Fair Disclosure Wire, (June 15).

Ruff, Gregory (2004), “The One Number That Matters," IBD Network newsletter, (June), [available at http://whatcounts.com/ bin/archive_viewer?id=61DE659B801A889DF22C59DD8997 8C54].

Rust, Roland T., Valarie A. Zeithaml, and Katherine N. Lemon (2000), Driving Customer Equity. New York: The Free Press.

Satmetrix (2004), "The Power Behind a Single Number: Growing Your Business with Net Promoter," Satmetrix Systems white paper, (accessed March 1, 2007), [available at http://www. satmetrix.com/pdfs/netpromoterWPfinal.pdf].

Schwarz, G. (1978), "Estimating the Dimension of a Model," Annals of Statistics, 6 (2), 461-64.

Singh, Jagdip (1995), "Measurement Issues in Cross-National Research," Journal of International Business Studies, 26 (3), 597-619.

Steenkamp, Jan-Benedict E.M. and Hans Baumgartner (1998), "Assessing Measurement Invariance in Cross-National Consumer Research," Journal of Consumer Research, 25 (June), 78-90.

Tobin, J. (1969), "A General Equilibrium Approach to Monetary Theory," Journal of Money, Credit and Banking, 1 (January), $15-29$.
Vandenberg, Robert J. (2002), "Toward a Further Understanding of and Improvement in Measurement Invariance Methods and Procedures," Organizational Research Methods, 5 (April), 139-58.

Varki, Sajeev and Roland T. Rust (1997), "Satisfaction Is Relative: Apply Analysis of Variance Techniques to Determine if Your CSM Scores Measure Up," Marketing Research, 9 (Summer), 15-19.

The Wall Street Journal (2006), "Best Selling Books," (June 9), W6.

Wangenheim, Florian V. and Tomás Bayón (2004), “The Effect of Word-of-Mouth on Services Switching: Measurement and Moderating Variables," European Journal of Marketing, 38 (9-10), 1173-85.

Welch, Jack and Suzy Welch (2006), "Dialing for Growth," BusinessWeek, (October 30), 134.

WOMMA (2005), "Applying the Golden Rule for Good Profits: 5 Tips from Bain \& Company's Fred Reichheld," Word of Mouth Basic Training newsletter, (December 8), (accessed March 1, 2007), [available at http://www.womma.org/wombat/ newsletters/wombat_1.02.htm].

Wong, Nancy, Aric Rindfleisch, and James E. Burroughs (2003), "Do Reverse-Worded Items Confound Measures in CrossCultural Consumer Research? The Case of the Material Values Scale," Journal of Consumer Research, 30 (June), 72-91.

Yu, Larry (2005), "How Companies Turn Buzz into Sales," MIT Sloan Management Review, 46 (Winter), 5-6.

Zeithaml, Valarie A. (2000), "Service Quality, Profitability, and the Economic Worth of Customers: What We Know and What We Need to Learn," Journal of the Academy of Marketing Science, 28 (1), 67-85. 
Copyright of Journal of Marketing is the property of American Marketing Association and its content may not be copied or emailed to multiple sites or posted to a listserv without the copyright holder's express written permission. However, users may print, download, or email articles for individual use. 